\title{
Romance and Prejudice --- Comment on Contemporary University Students' Personality Value Orientation
}

\author{
Dejie Jiao \\ Dezhou University \\ Dezhou 253023, Shandong, China \\ Tel: 86-534-898-5655Ｅ-mail: dzxyjdj@sina.com
}

\begin{abstract}
This essay makes a survey on contemporary university students' personality orientation combined with changes of times. The main features of contemporary university students' personality orientation are multivariate and romance, utility and prejudice. Some suggestions about cultivating healthy personality are made in this essay.
\end{abstract}

Keywords: University students, Personality, Value orientation, Romance, Prejudice

Since 1990s, as a result of China's further opening to other countries, degree of freedom in choice of economic development forms has been on the increase, and there has gradually emerged the characteristic of diversification in social culture. Political and cultural concepts youth undergraduates contact and feel have presented a tendency of diversification. In the $21^{\text {st }}$ century, penetrability influences of Internet on psychology and personality value orientation of university students are being more and more tremendous. In combination with changes of the times, the author in this article makes a survey on contemporary university students' personality value orientation, and proposes his own views about cultivation of a healthy personality in university students.

\section{Multivariate and romance}

Personality is a comprehensive concept with combination of physiological, psychological and social behaviors, etc, a sum of inner quality and outer behavior, and a particular self formed in the socialization process. Personality has its relative stability, and meanwhile its plasticity, which decides soundness of a personality and which lasts through all one's life. A sound personality is a kind of state attained by the natural instinct bestowed by biological evolution in its sufficient development, and is a value goal people should pursue.

As is well known, personality development of university students has obvious variability, and its changing motives are owing to two aspects. On one hand, it is affected by economic, political and cultural backgrounds of the society. On the other hand, it is confined by the level of knowledge they accept, concepts, aesthetic assessment and understanding of things. It is a product of objective and subjective combination. The process of its changes fully proves that, the process of the social development is actually the process of humans' gradual development, a process of their liberation, and a process in which human nature is gradually released, their personality gradually stands out and they go toward comprehensive development step by step.

From the foundation of the PRC to 1980s, such dominant values as "being selfless", "non-egocentricity", "for others' interests", and "serve for the people whole-heartedly" had a decisive impact upon university students. At the same time, China then hadn't been completely opened to the outside world, so university students' understanding of the outside concepts and thinking was a total blank. Therefore, they couldn't or dare not go one step beyond the social dominant concepts of that time. Their personality was always displayed as being uni-directional, undisturbed, and conformity. As for those unwilling university students, it was easy to implement social mobilization on them, which always ended up with an effect of going into action in their hundreds.

Since 1990s, as a result of China's further opening to the outside world, degree of freedom in choice of economic development forms has been on the increase, and there has gradually emerged the characteristic of diversification in social culture. Political and cultural concepts youth undergraduates contact and feel have presented a tendency of diversification. This characteristic of diversified tendency indicates that university students are able to choose their behaviors and socially adaptive ways according to their understanding of the times. They belong to a group who can 
adapt to social changes at the soonest, and their behavioral choice, psychological changes, and value changes can best reflect social realities of their times. Either they recognize the interest principle of the market economy, and go towards an extreme utility, or they approve the ideological absolutization of Plato and Hegel, and wish to realize spiritual aloofness through books. Either they agree with value standard of the Internet world, and respect scenery of the virtual world, or they identify the otherworldly happiness publicized by religions and convert their souls to delusion. Either they advocate challenges and thrill of life and promote risks, or they recognize value assessment of the knowledge economy, and select scientific innovation as their target. Either they advocate helpful belief of charity, and select to be volunteers as their profession, or they go towards personality distortion because they are not able to better adapt to social changes.

In the $21^{\text {st }}$ century, penetrability influences of Internet on psychology and personality value orientation of university students are being more and more tremendous. In this virtual world of Internet, what is presented to university students is a colorful kingdom. In this world, degree of an individual's freedom can be played to its perfection, and even the dominant ideal belief, moral standardization, and value assessment norm lose their meaning to them. They can select their thinking and concepts according to their will and emotion, so the dominant ideal belief, moral standardization and value norm etc are seen as one of cultural diversifications by them, without any particularity. Then when confronted with choices they have never met, they might make a judgment based on their existing value assessment standard, aesthetic sentiment, knowledge experiences, understanding ability, emotion and will, as well as psychological habit. That is, by that time, they have stepped into a more independent, free and liberal period, but meanwhile, people usually feel that there exists a flitting relation between them and the dominant core value norm of the society.

There is another key word in the characteristic of personality value orientation of contemporary university students, namely, "romance". Imagination is one of the major psychological characteristics among university students. Their value orientation or life choice is, without exception, brimmed with romanticism. Oscillation and lingering between idealism and realism are the most "romantic" among all choices. Romance is the performance form of personality in idealism. It's not specific, and it's both a style and a personality. Positive romanticism results in an ideal personality, while negative romanticism tends to result in distortion of a personality. Subjectively, all intelligent elites have been full of responsibility and mission towards the society. This inner motion forces them to reflect over and study on newly born theories and realities. In the $21^{\text {st }}$ century, the contemporary university students are no longer trapped in "tower of ivory", and are not bookworms who "are regardless of external trivialities, but engrossed in books by the lofty and sagacious". They have already regarded as the highest target in their university life stepping into the society, participating in social practices, strengthening a close contact with the society so as to train their comprehensive capacity, and improving their overall quality. Therefore, there is nothing new in it that university students begin an undertaking or take a part-time job. There is no doubt that, a part-time job plays a significant role in training of their capacity in all aspects, and is helpful to improve their comprehensive quality and development. Especially, education in the $21^{\text {st }}$ century calls for talents with capacity in all aspects. More and more university students attach great importance to and pursue their value dignity and interest requirement, and their self-consciousness, aggressiveness, achievement desire and self-responsibility are strengthened obviously.

\section{Utility and prejudice}

Personality value choice of university students is usually made in a conflict of seity and sociality, self-regard and altruism, individualism and collectivism, demand and contribution, personal standard and social standard. The keytone carried forward by the socialism dominant values is a value orientation of collectivism. However, development and open-door to the outside world of market economy have brought value ideology of humanism, which, in turn, intensifies the self-made and self-struggling consciousness of university students, and which also causes their value concepts to divert from social standard to personal standard. Therefore, some of them merely pay attention to assurance and satisfaction of their personal interests, personal desire and emotional requirement, indifferent to collectivism values, national consciousness and responsibility consciousness. Some individuals are even biased toward extremely personal standard, centering with themselves, regardless of national interests, collective interests and interests of others.

Since 1990s, reform and opening-up of China has entered a fast lane, and its social economy has been rapidly developed. However, at the same time, extreme utilitarianism, fickleness and mammonism also gradually become evident, whose impacts are widely reported and speculated. Driven by economic interests, a large number of scholars, teachers and university students plunge into the commercial sea. Even some specialized fields in universities also begin to cater to the social atmosphere of utility, which are changed into such hot majors as economic management, computer technology, advertisement project, and secretary, etc,. What are laid in bookstores and on bookshelves in universities are all books about investment, speculation in the stock market, successful experiences of Carnegie, rich fathers and poor fathers, etc,. Employment choice of university students is transferred from administrative units into enterprises, especially foreign-investment enterprises, which indicates fully that, utility, practicability and fickleness are penetrated in the willing personality of university students. 
Part of university students have no clear idea of their position in the society, their responsibility towards the society and the expectation of the society on them. Therefore, either they have high expectation upon themselves, blindly conceited, or underrate themselves, so once confronted with frustration, they are unable to recover themselves. On the other hand, there lacks a kind of master spirit among lots of university students, which is mainly manifested in the fact that, whether in their choice of the career, their grasp of knowledge or their communication with others, there exist utility of value concept, practicability of the value orientation and short-termism of value target. As for them, reading is just for making money, and making a fortune is their unique target, believing in the philosophy of "earning money desperately", "spending money desperately", "working desperately", and "playing desperately". They believe that what exists between people is merely monetary relation, and backscratching relation. They respect those wealthy tycoons and top notches, and set them as an example for themselves. Therefore, they are quite indifferent to collectivism concepts, and to the prospects and the country as well as to the ideal of human kind. There lacks a basic responsibility and mission in them, because they merely focus on realization of their own interests and their personal value. Therefore, they do business in the campus, work for others outside the school, with their school work dilapidated, or they are addicted to online games all day.

Many university students have a serious tendency of double personality. The so-called double personality refers to the two different attitudes and methods adopted on the same matter in the presence of different subjects, and also inconsistency of words and deeds. What is manifested in university students is the general phenomenon that they say they will comply with disciplines and public morality in the presence of others, but once not supervised, they are not able to consciously abide by disciplines and social public morality. For instance, when in a bus, they don't offer their seats to the old, the weak, the young and the disabled, and they throw litter about in public places, etc, especially the phenomenon of cheating in taking an exam can't be inhibited, because their cheating means are continually updated, and some students even make use of high-tech equipment to cheat, without any psychological burden.

Besides, most of contemporary university students are an only child in their family, so their socialization process lasts relatively long. Some even enter the university without finishing this process, so such bad qualities as capriciousness, arrogance and effemination still exist. The personality formed thereby is actually a reliance on the family, school and teachers. Whenever confronted with problems, difficulties or frustrations, what they choose is to pin their hope on others to resolve issues, but not to try their best to resolve them by themselves. The defect personality development produced because of dependence is mainly reflected as follows: wishing to get help from others; wishing to get affirmation from others; dependence on others; muddleheaded behavior when encountering difficulties, unable to make a decision independently; having no ideas of themselves, just following others blindly; afraid to get refused and sensitive to criticism from others, etc,. It is reported that, a university student who is the only child in his family enters the university, and his parents put her luggage on the bed, leaving and forgetting to make the bed for him. When it's time for bed, this student unexpectedly weeps against a pile of luggage. It is only after his roommates ask for they reason that they realize he can't fall into sleep just because he is not able to make the bed. And the reason why he utters a stifled cry is that he feels aggrieved.

From primary school until the university, exam performance has always been the major standard for selecting the best student and for assessment on them. Without a good exam performance, it is useless even if one is good at others aspects; with a perfect exam performance, one can still enter a university as long as he/she is not too bad in other respects. This wrong idea causes students only to make efforts in their study, but neglect their self-cultivation in conducting themselves and in their thinking and morality. In the university, although the pressure is not so much as in the elementary and secondary school, the ideology of intellectual education being the first is still serious. In some universities, they only focus on education of major courses, and such public courses as virtue education have become dispensable. These harmful trends and wrong doings finally bring about such phenomena: some students are self-centered, and lack a consciousness of caring about others as well as a collective consciousness; some are lacking in basic social and public morality. As for part of postgraduates and $\mathrm{Ph}$. D candidates, their humanistic cultivation, etiquette cultivation and cultivation of ethic thought even don't coincide with their educational backgrounds.

Prejudice of the personality value orientation in the contemporary university students is also reflected in their understanding and reflection of Chinese politics and history, and in the reverse direction of their value orientation, which emerges a personality of "rebellion".

On one hand, understanding of the facts enables university students to get mature in politics, in which they can analyze policies and political matters of the Party and look upon political leaders and cadres of the Party starting from corresponding social and historical conditions, making impartial and fair assessment. On the other hand, the fact that the former idealized worship gradually fades away, together with incessant corruption in reality, enables university students not to falsely believe in authority any more, and not long for perfection. Therefore, some psychological tendency evolves into a rebellion personality. As a matter of fact, the rebellion personality refers to the fact that one balances his personal vexation and sentiment caused by loss of a perfect target through opposite direction from the society. If not attached great importance, and not prohibited, the rebellion personality might result in harm to the social order. 


\section{Observation and leading}

Different times and societies have different requirements on personality of people. In ancient Greece, people regarded wisdom, bravery, temperance and justice as the connotation of a noble personality. The ancient Confucianism in China believed that benevolence, righteousness, propriety, wisdom, and faithfulness were perfect reflection of personality. Sun Yat-sen also mentioned in the Chinese Revolution period that faithfulness, piety, kindheartedness, good faith and peace were personality requirements of Chinese people. Contemporary university students bear a heavy cross-century historical burden, so they should strengthen their personal quality and perfect their personality.

Connotation of personality should coincide with progress of social development, and the greatest ideal of personality is necessarily all-round development of human beings. According to relative comments by Marx and Engels, all-round development of personality refers to the fact that each one should be fully developed and all their attributes should be developed. All-round development of humans includes that of their essence, demand, and quality. All-round development of the essence refers to enrichment and development of social attribute and social relations. All-round development of demand refers to unification of natural demand and social demand, unification of material demand and spiritual demand, and unification of individual demand and group (social) demand. All-round development of quality refers to coordinated development of the physical strength and intelligence, all-round development of social quality, capacity and quality as well as personality, namely, free development of the personality.

Shaping of an ideal personality in university students is a common responsibility of all educators in colleges. A perfect university education should provide a positive, united and synergic cultural atmosphere for individuals, activate underlying will of self-development in students, and lay a foundation for shaping of an ideal personality. University education should bring into full play the advantages of classroom teaching, and strengthen vigor of psychological health education. It is proved that, level of psychological health influences level of the personality development, and popularization of psychological health knowledge plays a significant role in training capacity of psychological adjustment and developing a perfect personality quality in university students. Furthermore, colleges should establish and make sound counselling institutions of psychological health, and train professional psychological counsellors, so as to provide professional counselling for various problems. This, not only can make target-oriented corrections on part of students with various personality problems, but can develop a supporting system among students by means of team counselling so as to help them establish an environment that is more helpful for personality development.

In addition, colleges should strengthen educational leading of interpersonal emotion among university students, and train their skills in handling interpersonal relations. During education and teaching, they should offer some opportunities of interpersonal communication by various means, and promote formation and improvement of their interpersonal communication skill through appropriate leading. In teaching, group cooperative learning, group discussion, role performance, and inquiry learning etc can practice their skills in communication with teachers and classmates. In spare time, extracurrlcular activities and extramural social practical activities can enable them to learn how to get along with others on various occasions. For example, a majority of students should be assigned a position, so that they can learn to come into contact with all kinds of people when fulfilling their own responsibility; more collective activities may create an opportunity for each student to communicate with others, which not only broadens their eyereach and practices their capacity, but also enables them to grasp the skill of interpersonal communication.

Thirdly, formation of a healthy personality can't be realized by mere learning in the university and the closed thinking of a saddhu. Man is a social animal, so a university student can't develop a sound and healthy personality without going out of the narrow environment of the university and throwing themselves into the tide of socialism market economy. Of course, we should pay attention to the duality of society in the formation and development of a personality. On one hand, gradual construction and perfection of the socialism market economic mechanism creates a favorable cultural atmosphere for shaping of a healthy personality in university students, and provides an active mechanism. Such trends as talent concept, justice concept, and benefit concept, etc, affect the positioning of their personality value, and promote them to care about the national and social progress. Their consciousness of supporting the policy of reform and opening-up, participation consciousness and competitiveness consciousness are largely intensified, and their internal vitality such as learning initiative and creativity is stimulated. They eager for independence, self-reliance, and they have strong maturity consciousness. They are in pursuit of self-perfection of life value, not only focusing on material interests, but worshipping spiritual civilization and concentrating on moral cultivation. They not only lay stress on development of personality, but care about destiny of the nation. On the other hand, social transformation and disbenefit of market economy also push part of students into perplex and confusion. They come into conflict with social development, and unconformity between behaviors and concepts emerges, and also such phenomena as personality distortion, etc,. Therefore, in social practice, teachers should pay attention to their observation, and conduct positive leading. We should strengthen concentration on thinking conditions of the social elite group, grasp accurately changing situations of their personality development, lead correctly their value orientation, and lay a reliable talent foundation for establishing a harmonious society and creating a perfect human environment. 
In a word, cultivation of university students' personality includes leading the core value judgment, establishing a farseeing ideal, and practicing a positive and healthy personality. This not only embodies a unified directivity of social progress, but also reveals diversity of personal development of the subject, which is the necessary direction of human social development.

\section{References}

Fu, Baoying. (2004). Impact of Maslou's Theory of Self Realization Upon Contemporary College Students in China. Education and Modernization, (2).

He, Sihong. (2007). Analysis of Personality Change Path of University Students after the Reform and Opening-up. Xiangchao (The second half month) (Theory), (5).

Li, Lingfen. (2003). The Students' Free Development and Full-scale Development in the Process of Higher Education. Journal of Heze Teachers College, (1).

Lu, Weiwei. (2004). Self-Consciousness, Self-Descipline, Independence and Freedom --- On Approaches of "Self Realization" in University Students. Journal of Shaoxing College of Arts and Sciences, (11).

Tian, Hongyu \& Ma, Wenying. (2004). Personality Characteristics of Modern Young Students and the Moral-Education Work. Journal of Liaoning Educational Administration Institute, (1).

Xie, yujin. (2006). The Subjective Predicaments of College Student in Virtual Communication of Network and Its Settlement. Journal of Beijing Youth Politics College, (4).

Yang, Xioamei. (2007). Study on University Students' Ideal Personalities and Their Shaping Approaches. Education Exploration, (7).

Yu, Kai. (2002). The Contemporary University Education in the Philosophical Perspectives. Comparative Education Review, (10). 